\title{
Association of ESR1 polymorphism rs2234693 and rs9340799 with Postmenopausal osteoporosis in a Chinese Population
}

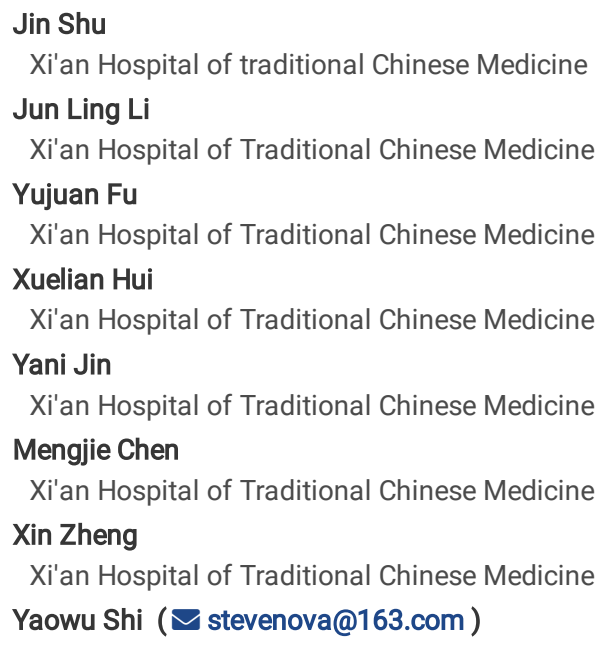

Xi'an Hospital of Traditional Chinese Medicine

Yani Jin

Xi'an Hospital of Traditional Chinese Medicine Mengjie Chen

Xi'an Hospital of Traditional Chinese Medicine Xin Zheng

Xi'an Hospital of Traditional Chinese Medicine Yaowu Shi ( $\sim$ stevenova@163.com)

Research article

Keywords: Postmenopausal osteoporosis, ESR1, Polymorphism, Meta-analysis, Genotype

Posted Date: March 17th, 2020

DOI: https://doi.org/10.21203/rs.3.rs-17530/v1

License: (9) (7) This work is licensed under a Creative Commons Attribution 4.0 International License. Read Full License

Version of Record: A version of this preprint was published at BMC Musculoskeletal Disorders on June 3rd, 2020. See the published version at https://doi.org/10.1186/s12891-020-03359-2. 


\section{Abstract}

Background Postmenopausal osteoporosis (PMO) is the most common type of primary osteoporosis. ESR1 polymorphism rs2234693 and rs9340799 has been widely studied as a candidate gene associated with PMO, however, the findings were inconclusive. The present study aims to explore the relationship of ESR1 polymorphism rs2234693 and rs9340799 with PMO risk in a Chinese Han population.

Methods A total of 230 unrelated PMO patients and 150 control were recruited. DNA of all participants was extracted from the peripheral blood samples and genotyped by Mass Array method. A meta-analysis of case control studies was also conducted to further elucidate the relationship of polymorphism with PMO.

Results Our results revealed that there were no associations of the rs2234693 with PMO. However,GG genotype of rs9340799 was associated with a higher risk of $\mathrm{PMO}(\mathrm{OR}=1.51,95 \% \mathrm{Cl}: 1.08-4.34, \mathrm{p}=0.03)$, even adjusting for risk factors $(\mathrm{OR}=1.83,95 \% \mathrm{Cl}: 1.12-5.04, \mathrm{p}=0.04)$. Logistic regression analysis showed the dominant model was associated with a higher risk of $\mathrm{PMO}(\mathrm{OR}=2.07,95 \% \mathrm{Cl}: 1.02-5.16, \mathrm{p}=0.02)$ after correcting the risk factors $(\mathrm{OR}=2.14,95 \% \mathrm{Cl}: 1.12-5.64$, $\mathrm{p}=0.04)$; In addition, the Meta-analysis results revealed that both two polymorphisms were not associated with PMO.

Conclusion In conclusion,ESR1 polymorphism rs9340799 was associated with PMO, However, well designed study with larger sample sizes, is required to further elucidate these association.

\section{Background}

Postmenopausal osteoporosis (PMO) caused by estrogen deficiency, is the most common type of primary osteoporosis which affects more than $40 \%$ of postmenopausal women[1-3]. As a typical senile disorder with decreasing bone-mineral density (BMD) and microstructural abnormality, PMO may lead to an increased risk for nonstress fractures[4]. Although, PMO is close related to estrogen levels following menopause, many factors, such as genetic elements had play important roles in the risk of osteoporosis $[5,6]$. Among these factors, genetics are found to play a pivotal role in the occurrence of osteoporosis and have received highly attention[6]. Twin studies in adult Caucasian woman revealed that the heritability of BMD might be between 50 and $85 \%[7]$. Genome-wide association study also reported that almost 400 single nucleotide polymorphisms (SNPs) distributed in more than 150 different loci, were associated with low BMD and osteoporosis, [8].

Estrogen activity is modulated through estrogen receptor $\alpha(E R-a)$ and $\beta$ (ER- $\beta)$ which are encoded by ESR1 on chromosome 6q25.1 and ESR2 on chromosome $14 q 23.2$ respectively $[9,10]$. Both ER- $\alpha$ and ER- $\beta$ isoforms are expressed in osteoblasts, osteoclasts, and bone marrow stromal cells[11, 12]. However, ESR1 is the major mediator of estrogen action in bone and has been widely studied as a candidate gene associated with PMO [13]. Two polymorphisms rs2234693 and rs9340799 had been reported to close related with PMO, however, these findings were inconclusive [14-16]. Mondockova et al. had reported that the rs9340799 was significantly associated with BMD at the femoral neck [17], whereas, another study by tanriover et al. had showed that no relationship of the two genes with PMO [18]. In addition, another study by Tang et al. in a meta-analysis showed that the ESR1 rs2234693 T allele may increase the risk of hip fracture, but the rs9340799 polymorphism was not associated with hip fracture[19]. Thus, to draw a more precise association of ESR1 polymorphism $\llbracket$ rs2234693 and rs9340799』with the risk of PMO, we sought to assess the impact of ESR1 polymorphism with POM and determine a possible association in postmenopausal Chinese women in a case-control study.

\section{Methods}

A total of 380 unrelated postmenopausal women over 45 years old were recruited from the outpatient of Xi'an Hospital of Traditional Chinese Medicine. All the subjects should menopause at least one year before enrollment. BMD was measured by DAX (GE company) and osteoporosis was diagnosed under World Health Organization criteria. Briefly, a T-score above - 1 standard deviation (SD) was considered normal and below - 2.5 SD as osteoporosis. All participants were divided into healthy group and osteoporosis group according to BMD results. Individuals with serious illness and those who accepted hormone replacement therapy (HRT) or drugs (bisphosphonates, steroids, thyroid hormones or GnRH analogs et al.) which may affect bone mass were excluded. Information about risk factors such as body mass index (BMI), menarche, menopause, family and personal history of fractur, smoking habits and alcohol habits were also collected. This study was approved by the Ethical Committee of Xi'an Hospital of Traditional Chinese Medicine and all the researches were performed in accordance with the Declaration of Helsinki.

\section{Genotyping}

Fasting blood samples were collected by using EDTA anticoagulant tube and stored at $-80^{\circ} \mathrm{C}$. DNA was extracted using a commercial kit (Qiagen, Hilden, Germany) according to the manufacturer's protocol. Genetic polymorphisms were identified on the Agena MassARRAY system (Agena/Sequenom Inc., San Diego, CA, U.S.A.).

\section{Meta-analysis}

Five electronic databases including PubMed, EMBASE, ISI Web of Science, National Knowledge Infrastructure (CNKI), and Wanfang Data were searched for studies to include in meta-analysis. MeSH and title/abstract were used for all eligible studies search. The references were hand searched simultaneously if necessary. Studies included in our meta-analysis need to satisfy the following criteria: (1) studies that conducted in human subjects; (2) sufficient data provided for calculating the crude odds ratios (ORs) and $95 \%$ confidence intervals ( $95 \% \mathrm{Cls}$ ). Correspondingly, the exclusion criteria were as follows: ( 1 ) studies without detailed genotype data; (2) reports with overlapping data.

Page 2/11 


\section{Statistical analysis}

All statistical analyses were performed by SPSS (version 18.0, SPSS Inc., Chicago, USA). Hardy-Weinberg equilibrium (HWE) were examined using the $\chi 2$ test. Demographics variables and genotype frequencies between groups were evaluated by student's $t$ test (for continuous variables) or Chi-squared test (for categorical variables). In addition, multiple logistic regression analyses were also performed to assess the association between osteoporosis as an outcome and risk factors including the ESR1 polymorphism. Confounding factors were also calculated, including gender, age, BMI, smoking and drinking habit.

Meta-analysis was using STATA version 12.0 (STATA Corporation, College Station, TX, USA). Heterogeneity was evaluated by $I^{2}$ statistic. If $I^{2}<50 \%$, the fixed effect model was used, otherwise, the random-effect model was adopted to calculate the pooled ORs. Pooled ORs and $95 \%$ Cls were calculated under the following genetic models: (1) allele, (2) recessive, (3) homozygous, (4) heterozygous, and (5) dominant. Publication bias was assessed by Begg's funnel plots. The significance was set to a $\mathrm{p}$-value of $<0.05$.

\section{Results}

\section{Characteristics of the study participants}

A total of 230 patients and 150 control were recruited for this hospital-based case-control study. All patients were Chinese with confirmed DXA for diagnosis of PMO. There was significant difference of BMD of total hip T-score between patients and control group $(p<0.01)$. No deviation from the HWE was observed (HWE $=0.97$ ) in the control groups. In addition, no significant difference of smoking and drinking ratio were observed between patients and control group. The demographic and clinical characteristics of the participants were shown in Table 1.

Table 1

The basic characteristic of the participants.

\begin{tabular}{|llll|}
\hline & Control & PMO & p \\
\hline Age & $54.62 \pm 4.43$ & $57.32 \pm 6.62$ & 0.06 \\
\hline BMI & $21.26 \pm 1.25$ & $24.5 \pm 3.21$ & 0.043 \\
\hline Age of menopause & $47.32 \pm 5.69$ & $49.52 \pm 7.232$ & \\
\hline Years since menopause & $5.21 \pm 2.14$ & $6.32 \pm 1.98$ & \\
Age of menarche & $12.65 \pm 1.21$ & $12.31 \pm 1.72$ & \\
\hline Total hip T-score & $-0.74 \pm 1.16$ & $-3.34 \pm 1.01$ & $<0.001$ \\
\hline Diabetes & $10 \%$ & $15.6 \%$ & \\
\hline Hypertension & $17.12 \%$ & $19.54 \%$ & \\
\hline Smoking(\%) & $1.1 \% \%$ & $0.9 \%$ & 0.13 \\
\hline Drinking & $1.5 \%$ & $1.2 \%$ & 0.11 \\
\hline
\end{tabular}

\section{Genetics Association Analysis}

Genotype distribution of ESR1 gene polymorphisms (rs2234693 and rs9340799) between patients and controls are showed in Table 2. No significant differences were observed between patients and controls in the distribution of TT, TC, and CC genotypes of rs2234693 ( $p=0.29)$. Whereas, there was a significant difference in the distribution of $A A, A G$ and $G G$ of $r s 9340799(p=0.043)$. 
Table 2

The genotype of rs2234693 and rs9340799

polymorphism in $\mathrm{PMO}$ and control group.

Significant associations are marked in bold.

\begin{tabular}{|llll|}
\hline & Control & PMO & P \\
\hline rs2234693 T > C & & & \\
\hline TT & 59 & 79 & 0.29 \\
\hline TC & 70 & 105 & \\
\hline CC & 21 & 46 & \\
\hline T & 188 & 263 & 0.13 \\
\hline C & 112 & 197 & \\
\hline rs9340799 & & & \\
\hline AA & 83 & 116 & 0.043 \\
\hline AG & 52 & 103 & \\
\hline GG & 15 & 11 & \\
\hline A & 218 & 335 & 0.96 \\
\hline G & 82 & 125 & \\
\hline
\end{tabular}

To further elucidated the relationship of the polymorphism with PMO, a logistic regression analysis was also performed. We found that the patients carrying with GG allele of rs9340799 was significantly correlated with PMO morbidity (OR $=1.51,95 \% \mathrm{Cl}: 1.08-4.34, p=0.03)$. After adjusting for age, BMI, smoking and drinking habits, there was still significant association of $G G$ genotype $(O R=1.83,95 \% \mathrm{Cl}: 1.12-5.04, p=0.04)$ with PMO (Table 3$)$, whereas no significant difference was observed under the AG genotype ( $p>0.05)$; In addition, no significant association was observed in rs2234693 with PMO.

Table 3

The logistic regression analysis of rs2234693 and rs9340799 genotype with the PMO

risk.

\begin{tabular}{|c|c|c|c|c|c|c|}
\hline & OR & $95 \% \mathrm{Cl}$ & $P$ & $\mathrm{OR}^{*}$ & $95 \% \mathrm{Cl} *$ & $\mathrm{P} *$ \\
\hline \multicolumn{7}{|c|}{ rs2234693 } \\
\hline $\mathrm{TT}$ & Reference & & & Reference & & \\
\hline $\mathrm{TC}$ & 0.84 & $0.31-3.52$ & 0.08 & 0.86 & $0.421-3.91$ & 0.08 \\
\hline $\mathrm{CC}$ & 1.21 & $0.47-3.19$ & 0.42 & 1.35 & $0.58-4.22$ & 0.57 \\
\hline \multicolumn{7}{|c|}{ rs9340799 } \\
\hline$A A$ & Reference & & & Reference & & \\
\hline$A G$ & 1.15 & $0.31-3.52$ & 0.25 & 1.3 & $0.51-4.02$ & 0.28 \\
\hline GG & 1.51 & $1.08-4.34$ & 0.03 & 1.83 & $1.12-5.04$ & 0.04 \\
\hline
\end{tabular}

We also found a significant association of rs9340799 with PMO under the dominant model $(\mathrm{OR}=2.07,95 \% \mathrm{Cl}: 1.02-5.16, \mathrm{p}=0.02)$ even after adjusting for the risk factors $(\mathrm{OR}=2.14,95 \% \mathrm{Cl}: 1.12-5.64, \mathrm{p}=0.04)$. Nevertheless, no significant association of rs2234693 polymorphism with $\mathrm{PMO}$ was observed under dominant and recessive genetic model (Table 4). 
Table 4

The logistic regression analysis of the dominant model and recessive model with the risk of PMO. *Adjusting for age, BMI, smoking and drinking habit.

Significant associations are marked in bold.

\begin{tabular}{|lcccccc|}
\hline & OR & $95 \% \mathrm{Cl}$ & $\mathbf{P}$ & OR* $^{*}$ & $95 \% \mathrm{Cl}$ & $\mathrm{P}^{*}$ \\
\hline rs2234693 & & & & & & \\
\hline Dominant model & 1.14 & $0.59-1.83$ & 0.37 & 1.26 & $0.61-2.62$ & 0.54 \\
\hline Recessive model & 1.28 & $0.68-2.55$ & 0.41 & 1.50 & $0.81-3.56$ & 0.45 \\
\hline rs9340799 & & & & & & \\
\hline Dominant model & 2.07 & $1.02-5.16$ & 0.02 & 2.14 & $1.12-5.64$ & 0.04 \\
\hline Recessive model & 1.76 & $0.71-4.04$ & 0.22 & 1.91 & $0.89-4.87$ & 0.31 \\
\hline Note: * Adjusting for Age, BMl. Significant associations are marked in bold \\
\hline
\end{tabular}

\section{Meta-analysis Results}

A meta-analysis was also employed to further explore the relationship of ESR1 polymorphism with PMO. A total of 4 articles (including our results) were enrolled in the analysis (Fig. 1). The study characteristics included in the meta-analysis were listed in Table 5. The random effect model was employed under the dominant, recessive, homozygous, heterozygous and allelic model for rs2234693. Whereas, for rs9340799, only dominant model was found with heterogeneity, thus the fixed model was used in the other four genetic models. The meta-analysis results showed that there were no association of rs2234693 and rs9340799 with PMO ( $p>0.05)$. (Fig. 2 and Fig. 3). Publication bias evaluated by using Begg's test show that no significant publication bias exists ( $p>$ 0.05) (Fig. 3).

Table 5

Characteristics and genotype of the studies included in this meta-analysis.

\begin{tabular}{|c|c|c|c|c|c|c|c|c|c|c|c|c|}
\hline \multirow[t]{2}{*}{ Author } & \multirow[t]{2}{*}{ Year } & \multicolumn{2}{|l|}{ Age } & \multicolumn{5}{|c|}{ MPO rs2234693/(rs9340799) } & \multicolumn{4}{|c|}{ Control rs2234693/(rs9340799) } \\
\hline & & MPO & control & $\mathrm{TT} /(\mathrm{AA})$ & $\mathrm{TC} /(\mathrm{AG})$ & $\mathrm{CC} /(\mathrm{GG})$ & $\mathrm{T} /(\mathrm{A})$ & $\mathrm{C} /(\mathrm{G})$ & $\mathrm{TT} /(\mathrm{AA})$ & $\mathrm{TC} /(\mathrm{AG})$ & $\mathrm{CC} /(\mathrm{GG})$ & $\mathrm{T} /(\mathrm{A})$ \\
\hline $\begin{array}{l}\text { Wang et } \\
\text { al.[30] }\end{array}$ & 2017 & $\begin{array}{l}62 . \\
81 \pm \\
5.78\end{array}$ & $\begin{array}{l}\text { 64. } 21 \\
\pm 9.22\end{array}$ & $78 / 99$ & $53 / 36$ & $11 / 7$ & $209 / 234$ & $75 / 50$ & $59 / 93$ & $62 / 46$ & $30 / 12$ & $180 / 232$ \\
\hline $\begin{array}{l}\text { Pontin } \\
\text { et al.[16] }\end{array}$ & 2018 & $>40$ & $>40$ & $22 / 33$ & $56 / 39$ & $14 / 20$ & $100 / 105$ & $84 / 79$ & $20 / 17$ & $54 / 57$ & $18 / 18$ & $94 / 91$ \\
\hline $\begin{array}{l}\text { Cisneros } \\
\text { et al.[29] }\end{array}$ & 2019 & $\begin{array}{l}66 \pm \\
11.2\end{array}$ & $\begin{array}{l}58.1 \pm \\
8.4\end{array}$ & $91 /(\mathrm{N} / \mathrm{A})$ & $70 /(\mathrm{N} / \mathrm{A})$ & $19 /(\mathrm{N} / \mathrm{A})$ & $252 /(N / A)$ & $108 /(\mathrm{N} / \mathrm{A})$ & $91 /(\mathrm{N} / \mathrm{A})$ & $78 /(\mathrm{N} / \mathrm{A})$ & $27 /(N / A)$ & $260 /(N / A)$ \\
\hline $\begin{array}{l}\text { Shu et } \\
\text { al. }\end{array}$ & 2019 & $\begin{array}{l}57.32 \\
\pm 6.62\end{array}$ & $\begin{array}{l}54.62 \\
\pm 4.43\end{array}$ & $79 / 115$ & $105 / 96$ & $46 / 19$ & $263 / 326$ & $197 / 120$ & $59 / 93$ & $70 / 45$ & $21 / 12$ & $188 / 221$ \\
\hline
\end{tabular}

Figure 1

\section{Discussion}

Osteoporosis is a multifactorial disease, characterized by loss of tissue microarchitecture and low BMD. It has been estimated that $30 \%$ of women and $12 \%$ of men were affected by osteoporosis $[8,20]$. The most important adverse health outcome of osteoporosis is bone fractures. Women at postmenopausal stage are faced to extremely high risk of osteoporosis[21-23]. Several candidate genes, such as ESR1, the major mediator of estrogen action in bone, have been reported to be associated with BMD and osteoporosis [24-26]. Ioannidis et al. had revealed that ESR1 is a susceptibility gene for fractures[27]. However, the polymorphism of ESR1 with PMO was still inconclusive.

Studies to elucidate the ESR1 genetic contributions to PMO have continued for several decades. To a much lesser extent, the association between BMD and a polymorphism in the promoter region of ESR1, characterized by a variable number of studies and still not come to a unified conclusion. Mondockova et al. had found that rs9340799 polymorphism may contribute to decreased BMD in postmenopausal women in southern Slovakia[14]. Nevertheless, Wang et al. had showed that rs2234693 polymorphism but not rs9340799 was associated with PMO[21]. And Kurt et al. showed that both rs9340799 and rs2234693 polymorphism were contribute to the determination of bone mineral density in Turkish postmenopausal women[28]. In our study, we had found that the GG genotype and the dominant genetic model of rs9340799 were susceptible to PMO, whereas, no relationship was found in rs2234693. These results were partly in accordance with former studies.

Although our case-control study had got the positive conclusions of rs9340799 polymorphism with PMO, these results should be treated with caution. A metaanalysis was also conducted to further elucidate the relationship of disease and polymorphism. Our meta-analysis of pooled analysis had showed that either homozygote, heterozygote, recessive, allelic models or dominant of rs9340799 and rs2234693 were the risk factor of PMO. These may be attributed to a small 
sample size, different ethnic background and different examine methods. These data need to be replicated in a larger cohort, and functional studies will be necessary to investigate whether and how ESR1 gene polymorphism involved in the pathogenesis of PMO.

The rs2234693 and rs9340799 polymorphic sites are located in the promoter region of the first intron of ESR1 gene, and so far, their functional consequences are unknown[29]. Although case-control study had partly revealed the relationship of the polymorphism, its mechanism is still not clear. We speculate that introns may contain regulatory elements, and the mutation may cause methylation and finally influence the effect of ESR1.

The results of our study may help in identifying patients with potential PMO risk; however, several limitations should not be ignored. Firstly, as the quantity of the patients were not large enough, thus give rise to failure to achieve statistical significance of rs2234693. Secondly, all participants enrolled were recruited from hospital which might result in potential selection bias. Thirdly, some potential confounding factors which may overestimate or underestimate the effect of gene polymorphism. Eventually, the meta-analysis was only enrolled 4 relative studies, this may give rise to publication bias and finally influence the overall results.

\section{Conclusion}

We had reported a significantly correlation of ESR1 genotype distribution with PMO in a Chinese Han population. This result was partly in accordance with the meat-analysis results. However, this is only a preliminary conclusion, a larger cohort study and functional studies will be necessary to investigate whether and how the polymorphism might involve in the pathogenesis of PMO.

\section{Abbreviations}

PMO: Postmenopausal osteoporosis; BMD: Bone-mineral density; HRT: Hormone replacement therapy; BMI: Body mass index; HWE: Hardy-Weinberg equilibrium; $95 \% \mathrm{Cl}$ : 95\% confidence interval

\section{Declarations}

\section{Acknowledgements}

The authors thank all of the study subjects for volunteering to participate in the study.

\section{Authors' contributions}

JS produced the idea to this study and collected the samples. JL and YF did the literature search, screened the potentially eligible studies and evaluated the data from each included study, they both contributed equally to this work. XH was responsible for making the final version of this paper. JY made the statistics. MC, XZ and YS critically revised this manuscript.

\section{Funding}

This work was funded by National Natural Science Foundation of China (No. 81691877).

\section{Availability of data and materials}

The datasets generated and/or analyzed during the current study are not publicly available due to potential for individual and organizational privacy to be compromised. Reasonable requests for parts of the data will be considered by the corresponding author.

\section{Ethics approval and consent to participate}

Ethical approval was obtained from the Institution Review Board of the Xi'an Hospital of Traditional Chinese Medicine. All participants in this study were provided with explanations via face-to-face interpretation and a written informed consent was obtained before inclusion.

\section{Consent for publication}

All authors read and approved the final manuscript.

\section{Competing interests}

The authors declare that they have no competing interests.

\section{References}

1. Black DM, Rosen CJ: Clinical Practice. Postmenopausal Osteoporosis. N Engl J Med 2016, 374(3):254-262.

2. Liu H, Zhao H, Lin H, Li Z, Xue H, Zhang Y, Lu J: Relationship of COL9A1 and SOX9 Genes with Genetic Susceptibility of Postmenopausal Osteoporosis. Calcif Tissue Int 2019.

3. Rachner TD, Khosla S, Hofbauer LC: Osteoporosis: now and the future. Lancet 2011, 377(9773):1276-1287.

4. Zhuang HF, Wang PW, Li YZ, Lin JK, Yao XD, Xu H: Analysis of Related Factors of Brittle Hip Fracture in Postmenopausal Women with Osteoporosis. Orthop Surg 2020. 
5. Cai X, Yi X, Zhang Y, Zhang D, Zhi L, Liu H: Genetic susceptibility of postmenopausal osteoporosis on sulfide quinone reductase-like gene. Osteoporos Int 2018, 29(9):2041-2047.

6. Mitek T, Nagraba L, Deszczynski J, Stolarczyk M, Kuchar E, Stolarczyk A: Genetic Predisposition for Osteoporosis and Fractures in Postmenopausal Women. Adv Exp Med Biol 2019, 1211:17-24.

7. Zhai G, Andrew T, Kato BS, Blake GM, Spector TD: Genetic and environmental determinants on bone loss in postmenopausal Caucasian women: a 14-year longitudinal twin study. Osteoporos Int 2009, 20(6):949-953.

8. Hidalgo-Bravo A, Parra-Torres AY, Casas-Avila L, Jimenez-Ortega RF, Ramirez-Salazar EG, Patino N, Rivera-Paredez B, Salmeron J, Valdes-Flores M, Velazquez-Cruz R: Association of RMND1/CCDC170-ESR1 single nucleotide polymorphisms with hip fracture and osteoporosis in postmenopausal women. Climacteric 2019, 22(1):97-104.

9. Pinkas J, Gujski M, Wierzbinska-Stepniak A, Owoc A, Bojar I: The polymorphism of estrogen receptor alpha is important for metabolic consequences associated with menopause. Endokrynol Pol 2016, 67(6):608-614.

10. Goulart AC, Zee RY, Pradhan A, Rexrode KM: Associations of the estrogen receptors 1 and 2 gene polymorphisms with the metabolic syndrome in women. Metab Syndr Relat Disord 2009, 7(2):111-117.

11. Wu F, Zhou D, Shen G, Cui Y, Lv Q, Wei F: Association of VDR and OPG gene polymorphism with osteoporosis risk in Chinese postmenopausal women. Climacteric 2019, 22(2):208-212.

12. Jia M, Dahlman-Wright K, Gustafsson JA: Estrogen receptor alpha and beta in health and disease. Best Pract Res Clin Endocrinol Metab 2015, 29(4):557568.

13. Saoji R, Desai M, Das RS, Das TK, Khatkhatay MI: Estrogen receptor alpha and beta gene polymorphism in relation to bone mineral density and lipid profile in Northeast Indian women. Gene 2019, 710:202-209.

14. Mondockova V, Adamkovicova M, Lukacova M, Grosskopf B, Babosova R, Galbavy D, Martiniakova M, Omelka R: The estrogen receptor 1 gene affects bone mineral density and osteoporosis treatment efficiency in Slovak postmenopausal women. BMC Med Genet 2018, 19 (1):174.

15. Greendale GA, Chu J, Ferrell R, Randolph JF, Jr., Johnston JM, Sowers MR: The association of bone mineral density with estrogen receptor gene polymorphisms. Am J Med 2006, 119(9 Suppl 1):S79-86.

16. Pontin PA, Nogara PRB, Fonseca FCP, Cesar Netto C, Carvalho KC, Soares Junior JM, Baracat EC, Fernandes TD, Maffulli N, Santos MCL et al: ERalpha Pvull and Xbal polymorphisms in postmenopausal women with posterior tibial tendon dysfunction: a case control study. J Orthop Surg Res 2018 , 13(1):316.

17. Rojano-Mejia D, Coral-Vazquez RM, Coronel A, Cortes-Espinosa L, del Carmen Aguirre-Garcia M, Valencia-Villalvazo EY, Canto P: Relation of the estrogen receptor and vitamin D receptor polymorphisms with bone mineral density in postmenopausal Mexican-mestizo women. Gene 2014, 537(1):10-14.

18. Durusu Tanriover M, Bora Tatar G, Uluturk TD, Dayangac Erden D, Tanriover A, Kilicarslan A, Oz SG, Erdem Yurter H, Sozen T, Sain Guven G: Evaluation of the effects of vitamin D receptor and estrogen receptor 1 gene polymorphisms on bone mineral density in postmenopausal women. Clin Rheumato/ 2010, 29(11):1285-1293.

19. Tang L, Cheng GL, Xu ZH: Association between estrogen receptor alpha gene (ESR1) Pvull (C/T) and Xbal (AVG) polymorphisms and hip fracture risk: evidence from a meta-analysis. PLoS One 2013, 8(12):e82806.

20. Martin J, Viprey M, Castagne B, Merle B, Giroudon C, Chapurlat R, Schott AM: Interventions to improve osteoporosis care: a systematic review and metaanalysis. Osteoporos Int 2020.

21. Wang C, Zhang Z, Zhang H, He JW, Gu JM, Hu WW, Hu YQ, Li M, Liu YJ, Fu WZ et al: Susceptibility genes for osteoporotic fracture in postmenopausal Chinese women. J Bone Miner Res 2012, 27(12):2582-2591.

22. Anastasilakis AD, Polyzos SA, Yavropoulou MP, Makras P: Combination and sequential treatment in women with postmenopausal osteoporosis. Expert Opin Pharmacother 2020:1-14.

23. Bailey RL, Zou P, Wallace TC, McCabe GP, Craig BA, Jun S, Cauley JA, Weaver CM: Calcium Supplement Use Is Associated With Less Bone Mineral Density Loss, But Does Not Lessen the Risk of Bone Fracture Across the Menopause Transition: Data From the Study of Women's Health Across the Nation. JBMR Plus 2020, 4(1):e10246.

24. Li S, Jiang H, Du N: Association between osteoprotegerin gene T950C polymorphism and osteoporosis risk in the Chinese population: Evidence via metaanalysis. PLoS One 2017, 12(12):e0189825.

25. Bai WY, Wang L, Ying ZM, Hu B, Xu L, Zhang GQ, Cong PK, Zhu X, Zou W, Zheng HF: Identification of PIEZO1 polymorphisms for human bone mineral density. Bone 2020, 133:115247.

26. Kondo H, Fujino H, Nagatomo F, Ishihara A: Influence of estrogen receptor alpha polymorphisms on bone density in response to habitual exercise in Japanese postmenopausal women. ScientificWorldJournal 2014, 2014:593927.

27. loannidis JP, Ralston SH, Bennett ST, Brandi ML, Grinberg D, Karassa FB, Langdahl B, van Meurs JB, Mosekilde L, Scollen S et al: Differential genetic effects of ESR1 gene polymorphisms on osteoporosis outcomes. JAMA 2004, 292(17):2105-2114

28. Kurt O, Yilmaz-Aydogan H, Uyar M, Isbir T, Seyhan MF, Can A: Evaluation of ERalpha and VDR gene polymorphisms in relation to bone mineral density in Turkish postmenopausal women. Mol Biol Rep 2012, 39(6):6723-6730.

29. Farias-Cisneros E, Hidalgo-Bravo A, Miranda-Duarte A, Casas-Avila L, Rozental TD, Velazquez-Cruz R, Valdes-Flores M: COL1A1, CCDC170, and ESR1 single nucleotide polymorphisms associated with distal radius fracture in postmenopausal Mexican women. Climacteric 2020, 23(1):65-74.

30. Wang W, Cao J, Li YH: Association between Estrogen Receptor Alpha Gene (ERa)Polymorphism and Osteoporosis in Postmenopausal Women. Journal of Henan Medical College 2017, 29(1):11-15.

Page $7 / 11$ 
Figures

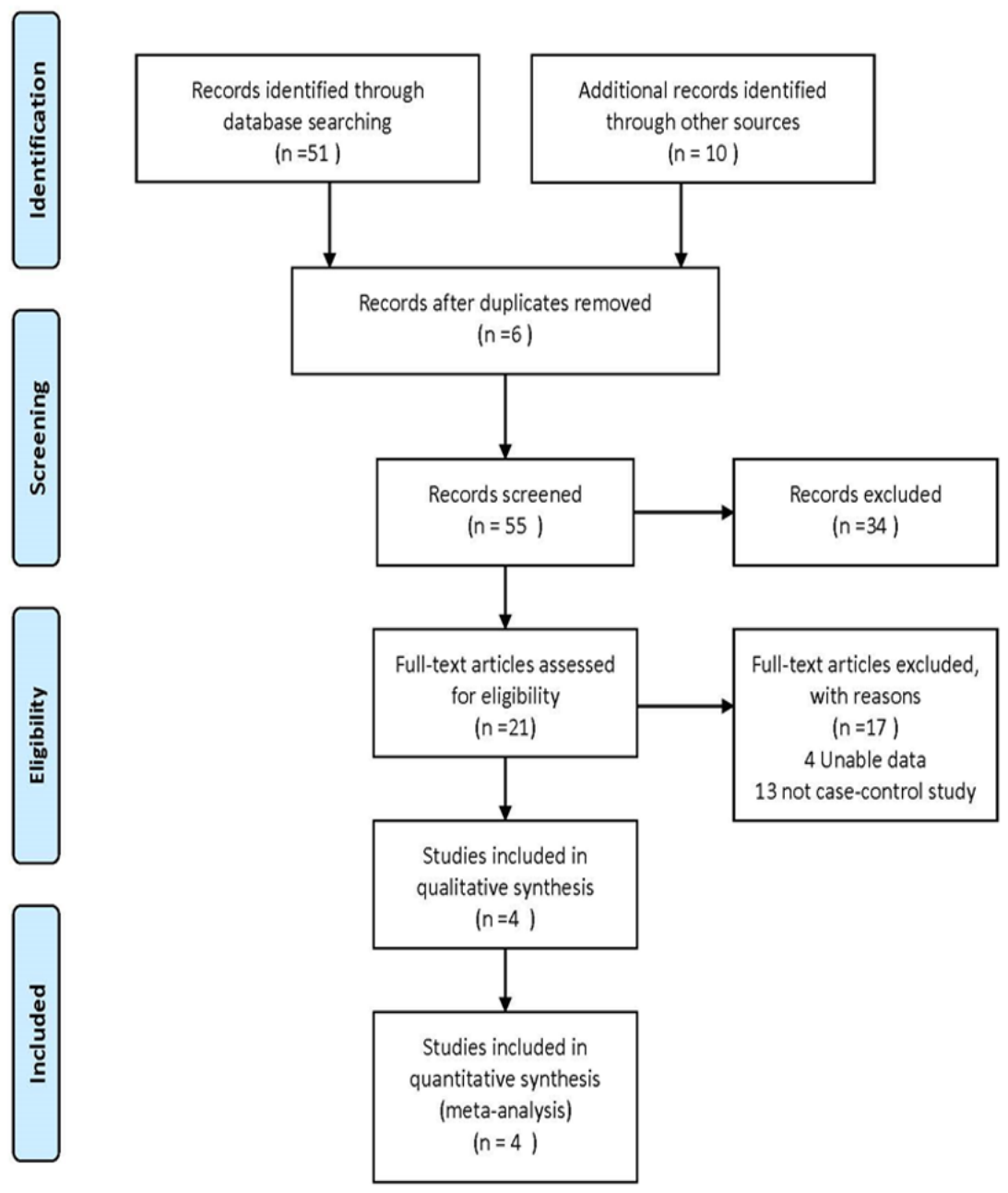

Figure 1

Flow sheet summarizing study identification and selection 

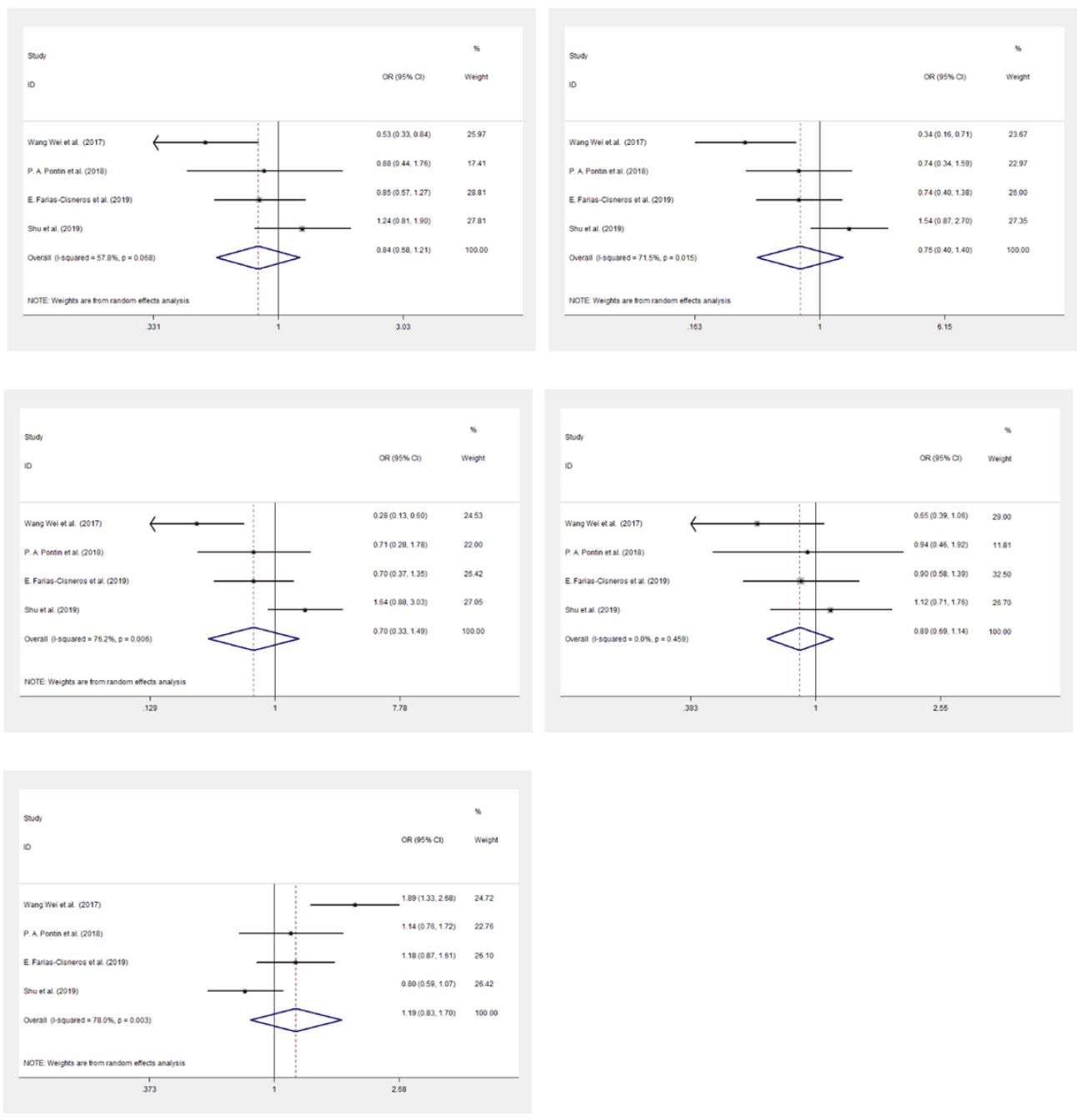

\section{Figure 2}

Forest plots of rs2234693 polymorphism under five genetic models. A is the dominant model; $\mathrm{B}$ is the recessive model; $\mathrm{C}$ is the homozygote model; $\mathrm{D}$ is heterozygote model; $\mathrm{E}$ is the allelice model. 

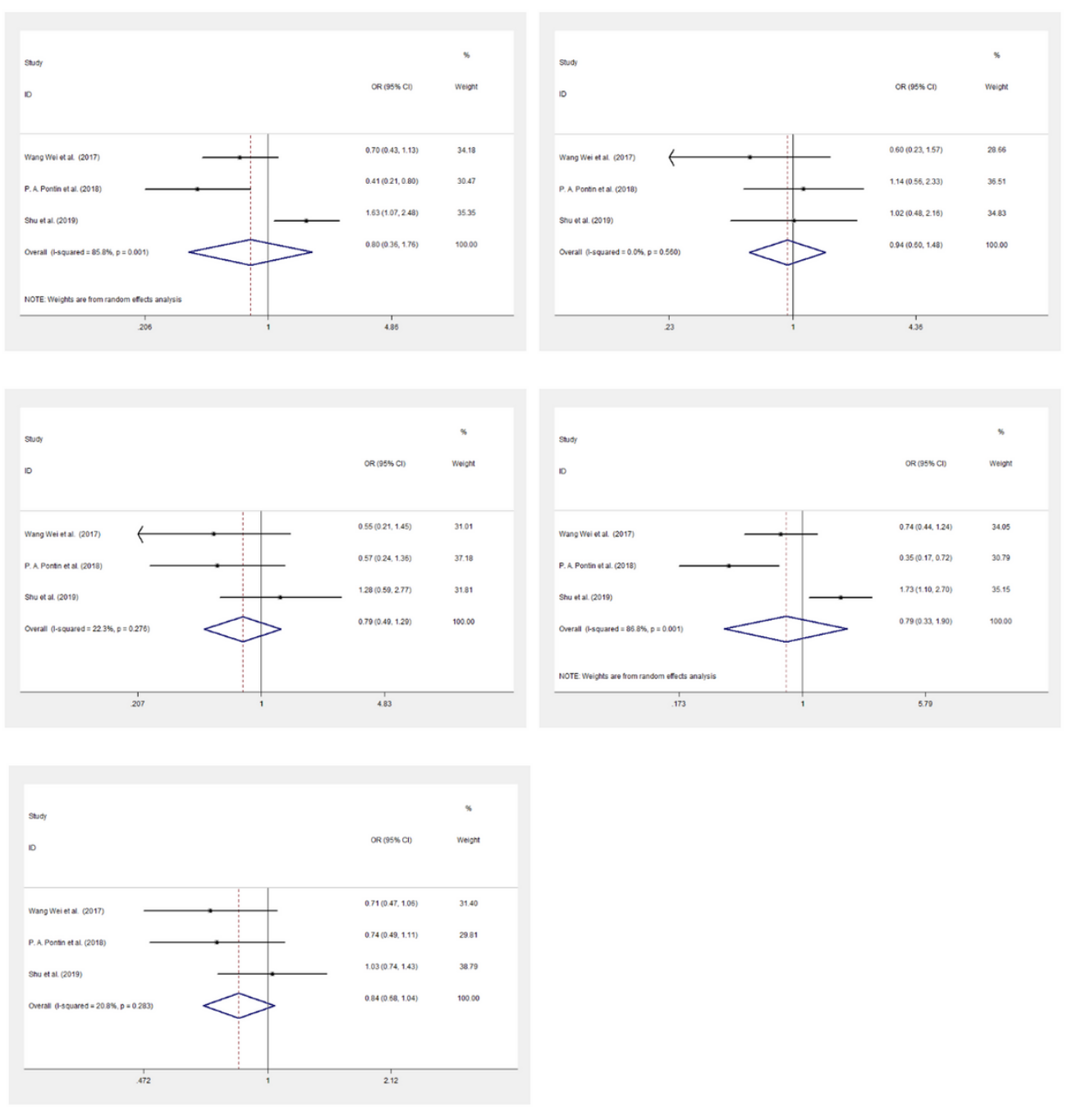

\section{Figure 3}

Forest plots of rs9340799 polymorphism under five genetic models. A is the dominant model; $\mathrm{B}$ is the recessive model; $\mathrm{C}$ is the homozygote model; $\mathrm{D}$ is heterozygote model; $\mathrm{E}$ is the allelice model. 

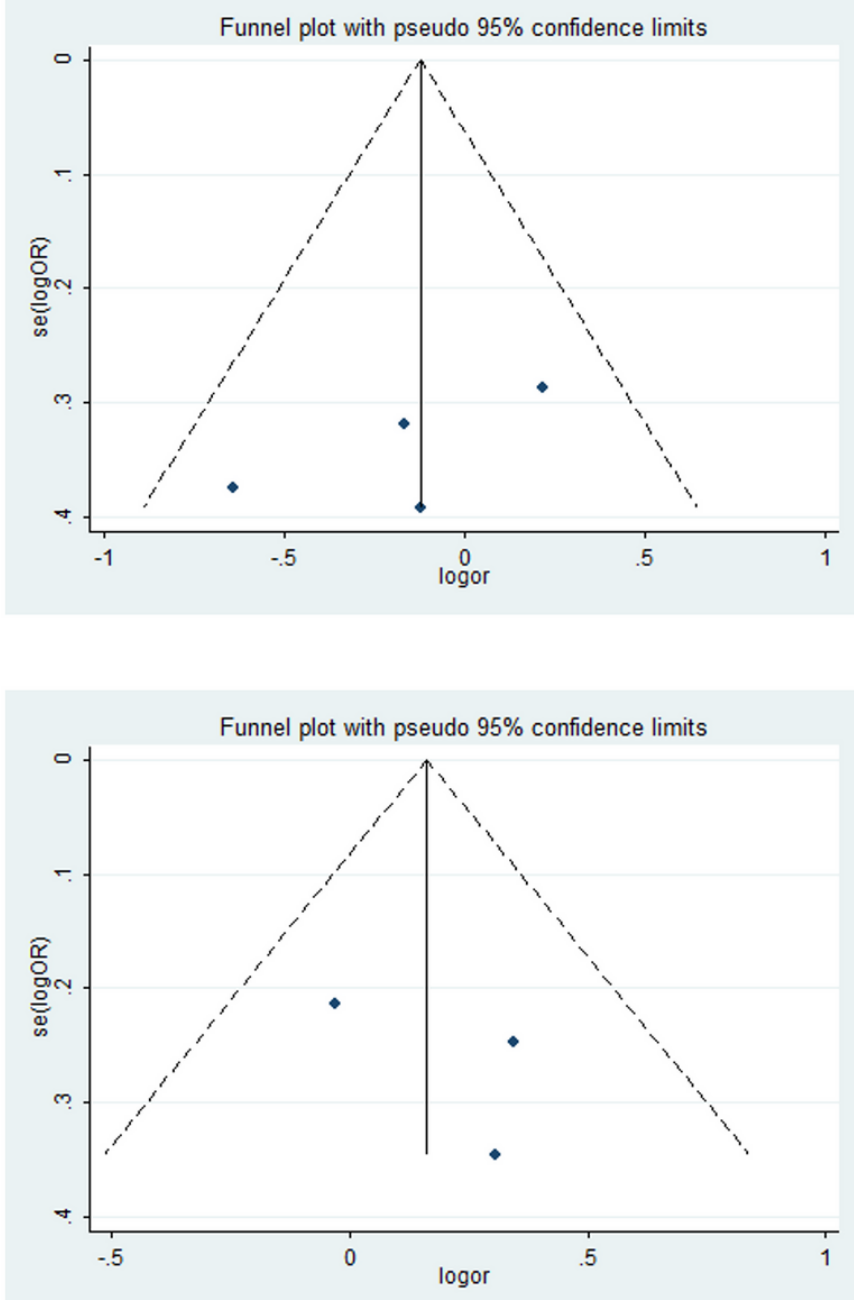

Figure 4

Begg's funnel plot for publication bias analysis (dominant model). 